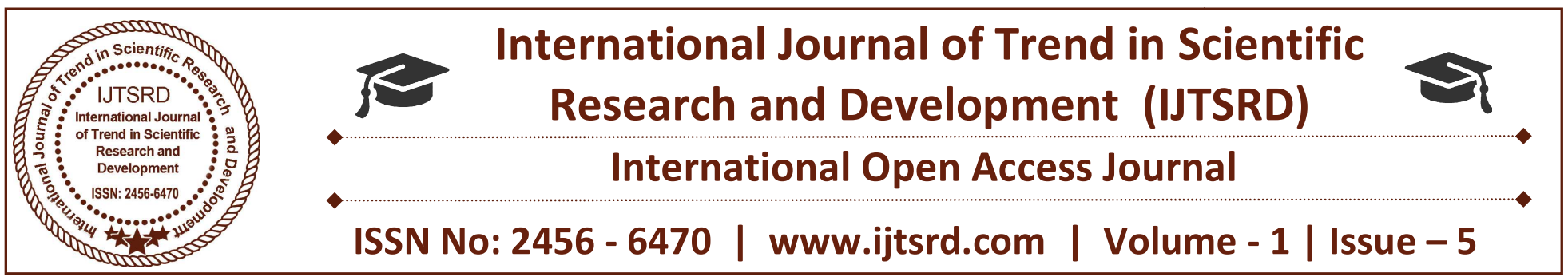

\title{
Effect of Price Subsidy on Nutritional Status
}

\author{
Divya Sharma \\ Masters in Economics, JNU
}

\author{
Supriya Anand \\ Mphil Economics, JNU
}

\begin{abstract}
Price subsidy program to enhance the calorie intake has been implemented in many developing countries since nutritional status plays a vital role in the labour productivity thereby affecting economic growth and development. The program fails to have the desired impact on nutrition as observed in India. Studies from other countries however, suggest that price subsidy can be an effective instrument in tackling nutritional deficiency. This literature review tries to address the question: How effective is price subsidy in improving the calorie intake of households?
\end{abstract}

\section{INTRODUCTION}

\section{RELATIONSHIP BETWEEN NUTRITION AND ECONOMIC GROWTH}

The idea of supporting the poor through the subsidy program is not only based on equity reasons but also on efficiency as low level of nutritional status leads to poor health which results in low productivity of labour and slow down economic growth and development. Therefore we need sustained access to nutritionally balanced food at all times in any economy (Valero \& Valero, 2014). (Leibenstien, 1957)showed positive relationship between food consumption and labour productivity. It is being empirically tested using data set consisting of forty households from six villages in rural farms of India. Using two SLS technique it was showed that calorie intake of female significantly increased the labor productivity (Aziz, August 1995). Thus we can say that if daily calorie consumption is increased, it will increase economic productivity. Katinka Weinberger (Weinberger) tested that calorie intake particularly the micronutrients effects overall economic productivity and growth by taking rural agricultural labour sample from India and inferred that iron intake significantly improved productivity of households.

This literature review focuses on the calorie improvement aspect of price subsidy due to the underlying importance of nutritional status for the welfare of households.

\section{PRICE SUBSIDY AND NUTRITIONAL STATUS}

Food expenditure accounts for a large share of total expenditure among the poor households, thus provision of food subsidy in the form of lower prices of calorie-rich staple crops is vital for overall economy's development. To capture the effect of price subsidy on the nutritional status of the recipient households there has been several studies based on different assumptions. AnjiniKochar(Kochar, 2005) found that there will be an increase in the calorie intake if there is a high take up rate in availing subsidy through PDS in India (which she explained by substitution and income effects). Another study by NeerajKaushal and Felix Muchomba looks at the different consumption pattern to analyse the efficacy of the TPDS program. On the other hand, Jensen and Miller noted in two provinces of China that if high proportion of subsidy is given then it can create large wealth effects for the recipients and usually it results in substitution towards non-nutritional attributes.

\section{PDS: LARGEST FOOD SUBSIDY PROGRAM IN INDIA}

The logic behind providing food subsidy by the government is that a reduction in prices by providing subsidy will cause a larger percentage increase in the 
International Journal of Trend in Scientific Research and Development (IJTSRD) ISSN: 2456-6470

real income of the poor households. In India PDS is the largest food subsidy program constituting $1 \%$ of GDP (Krishnamurthy, Pathania, \& Tandon, 2014).Under this program there is distribution of wheat, rice, edible oils, kerosene, and sugar at subsidized prices to poor households. The program evolved in the 1950sto stabilize the high fluctuating prices due to a nationwide shortage of food during that time. The central government procures the food grains through the Food Corporation of India (FCI), which purchases the food grains from farmers at the fixed minimum support price (MSP). The government also determines a uniform central issue price (CIP), at which it sells food grains from the FCI to state governments for distribution through the PDS(Radhakrishna, 1991).State governments are allowed to add distribution costs and taxes to the issue price. Program suffered from few errors of exclusion of intended recipient and inclusion of ineligible households. Therefore, in 1997 Targeted PDS was introduced to tackle this problem.

\section{EVALUATING THE EFFECT OF FOOD SUBSIDY ON CALORIE INTAKE}

Price subsidy given to the households result in two opposite effects: substitution effect and the income effect. These effects are opposite in the sense that substitution effect results an increase in the consumption of the subsidized good while the income effect results in increase in the consumers' real income and thus with increased real income, consumption of both subsidised as well as nonsubsidised goods should increase .Thus the overall effect of subsidies depend upon the relative magnitudes of these opposite effects. If income effect outweighs the substitution effect then the nutritional status of the recipient household will deteriorate since that household may divert its consumption to luxury food with low in calorie compound and non-food commodities thus, reducing the overall nutritional status. Another study by Kochar (Kochar, 2005)shows different result based on different assumption. She showed that substitution between participation rates by households devoting time in collecting the PDS grain and forgoing the wages which is the opportunity cost of participation is one of the factors that will affect the calorie intake.

(Kochar, 2005)suggested a theoretical model based on the assumption that consumption decisions of any household does not affect the market prices irrespective of the fact that they are affected by government procurement process. Thus, a change in prices due to government policy will not alter the effect of the PDS subsidy on household calorie consumption.

According to (Kochar, 2005) there is disutility due to the transaction cost which results in the low take up rates i.e households do not participate actively in this welfare program of the government. Transaction costs include the wage forgone by household members who devote their time in collecting PDS grains, walking time and the waiting time spent in queue at Fair Price Shops (Bunsha, 2002). If the households have valuation for leisure then the time spent on accession of food grains will be counted as transaction cost which will enter as a negative factor in the utility functions of household members. The intuition behind this is that reservation value of household member increases with food price subsidy, as they are forgoing the increased reservation wage for the PDS grains to avail the subsidy. Therefore, there is a negative effect on utility by reduction in leisure due to the wage effect even after controlling for total household consumption of food grains.

Therefore according to (Kochar, 2005)utility of a household will depend on food consumption (c) which includes the PDS grain also, purchase of PDS grain (qs) which will enter in utility function to highlight the transaction cost associated with accession of PDS grain and lastly utility will depend on set of other variables that determine the preferences. Other assumptions are: the PDS price (Ps) is less than the prevailing market price (Pm) and $\mathrm{Qs}_{\mathbf{s}}<=\mathrm{Q}$, the maximum amount available from FPS.

Utility is maximized subject to the budget constraint:

$\mathrm{C}=\mathrm{I}+(\mathrm{Pm}-\mathrm{Ps}) \mathrm{Qs}=\mathrm{E}$, where $\mathrm{E}$ is the expenditure and there are some additional constrained as well

$\mathrm{Qs}>=0$ \& $\mathrm{Qs}<=\mathrm{Q}$

First order condition of utility with respect to the food consumption (calorie intake) will give determinants for food consumption which will suffer from endogeneity problem as the total consumption of food depends negatively upon quantity of PDS grain purchased through its effect on leisure and the expenditure in turn depends on PDS grain qs. Hence the elasticity of food consumption with respect to PDS subsidy is different from expenditure elasticity.

Giving food subsidy will have both income effects and substitution effects. Income effects are well explained by the quantity purchased under PDS 
International Journal of Trend in Scientific Research and Development (IJTSRD) ISSN: 2456-6470

entering the budget constraint which entails the income effect. Substitution effect is explained by the transaction cost aspect: if the subsidy has an impact on the reservation wages of people who collect PDS grains from FPS; the inherent strategic complementarity between consumption of food (calorie intake) and time spend on work would imply that calorie intake will increase with the increment in subsidy after controlling its effect on household expenditures. Thus the net effect on calorie intake will depend on the resultant effect of both of income and substitution effects. If the PDS subsidy constitutes a meagre part of household expenditure, then substitution effect will be less which imply that the elasticity of consumption with respect to subsidy will be less than elasticity of expenditure. Therefore, according to Kochar (Kochar, 2005), nutritional status (through calorie intake) will improve if substitution of reservation wages to high take up rates (high participation in program) will take place.

Despite the ambiguities in the result of the model suggested by Kochar there are myriad of instances in India where this welfare program has little effects on calorie intake which are well explained by empirical studies on states.

There are states in which transaction cost element dominates and due to both demand and supply side constraints there is decline in calorie intake, while at the same time due to favourable conditions and composition of food subsidy and staple there is increase in calorie intake after the food subsidy of which Kerala is a prime example.

Jensen and miller(jensen, april 2008) focuses on the wealth effects created by the price subsidies which is on different lines from what kochar, as discussed above, Jensen argues that in the low developing countries poor households spend a major proportion of their budget on staple foods such as wheat, rice and coarse grains to meet their nutritional requirements, usually they are considered as the cheapest source of nutrition in terms of its monetary value. Large wealth effects are created as mostly subsidy is given on these same foods.

As we know that these wealth or income effects leads to shift away from the subsidised good. Thus, consumers might respond to the price subsidy by switching away from these nutritious staples, which are typically strongly inferior goods, and toward "luxury" foods (such as meat) which offer varieties in taste, but as the calorie content is very low, it results in weakening the intended nutritional impact of the subsidies.

Validity of this wealth effect is observed in the field experiment conducted by Jensen and miller (jensen, april 2008) for a sample of urban poor in two provinces of China, even for the poorest households the price subsidy had at best no effect on calorie intake, and actually worsened calorie intake among the poor. The motivating hypothesis for this study is that consumers may substitute away from calorie-rich foods to foods with higher content of non-nutritional attributes (i.e luxury food and non-food commodities). The situation is even worsened when large subsidies are given as higher substitution take place from the staple good. Thus these shortcomings clearly highlight that price subsidies doesn't lead to increase in calorie intake .However, proponents of price subsidy argues that subsidy leads to utility gains to the households, they are easier to target and have higher political support.

There are two major interpretations for these results from Jensen and Miller study. Firstly consumers are utility maximizers since they perceived that the gains from increased taste is greater than the calories lost, thereby affecting their long-term health status. This arises if consumers heavily discount the future, so they are willing to sacrifice long term health in favour of their short-term utility gains. Secondly consumers are unaware that they are losing nutrients in substituting from the calorie-rich cheap staple good to expensive foods. This happens because consumers are not fully aware of the exact calorie content of rice (staple) and meat (expensive non staple), and their belief that seafood is calorie rich than rice clearly shows their lack of knowledge. Since consumers are losing in calories, nutritional information can play a vital role in making consumers aware to make better choices, and thereby improving the nutrition from subsidies.

(kaushal \& Muchomba, 2013) Kaushal and Muchomba carry forward the points raised by Jensen and Miller, question the efficacy of food grains subsidy in improving the nutritional intake of the poor through a program targeting them namely, Targeted Public Distribution System (TPDS).

For the purpose of their study they have divided the sample into 2 groups: one, districts where the subsidized food (say, rice and wheat) is the staple food and another, districts where the unsubsidized 
International Journal of Trend in Scientific Research and Development (IJTSRD) ISSN: 2456-6470

food is the staple food (say, coarse grains). The following figure will explain how a food price subsidy affects different consumers.

\section{Fig (i)}

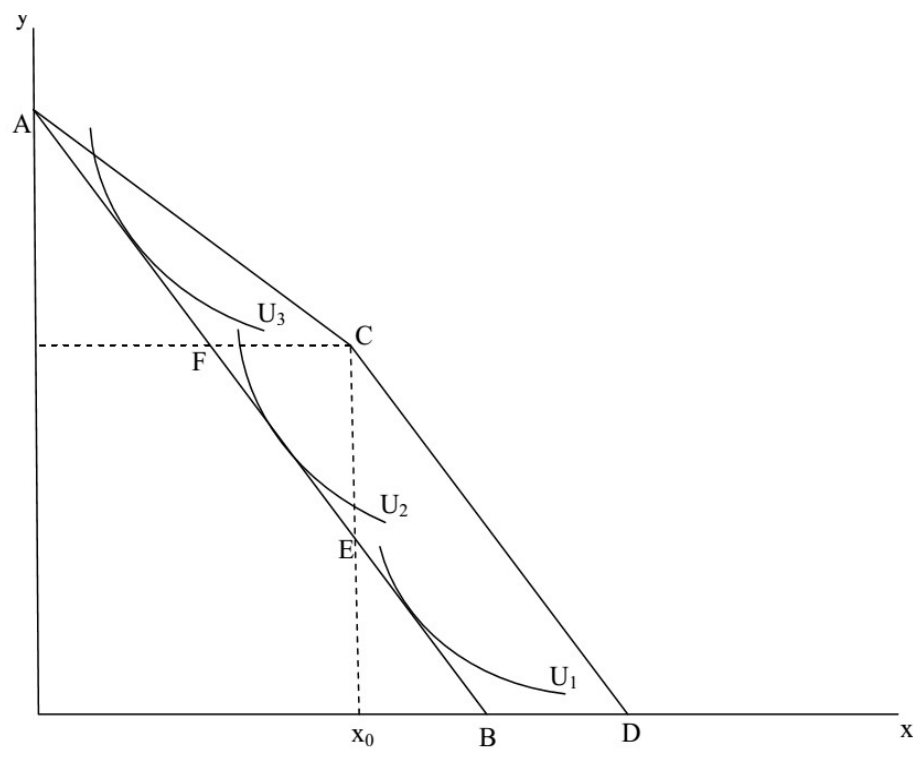

Figure (i) presents the indifference curves of 3 individuals in period $t$ given by $U_{1}, U_{2}$ and $U_{3}$. Consumer 1 , who is consuming more than $\mathrm{x}_{0}$ in the initial period, will experience only income effect since he will move to $\mathrm{CD}$ portion with the subsidy program. Consumer 2 could have a new equilibrium at either the $\mathrm{AC}$ or $\mathrm{CD}$ segment. Consumer 3 in the segment AF will move to point on AC after the subsidy. Considering $\mathrm{X}$ is rice and wheat; and $\mathrm{Y}$ is coarse grain, we observe from the figure above that in district where rice and wheat is a staple food, providing subsidy in rice and wheat will only have income effect with the market price as the marginal price faced by the consumers. In the districts with coarse grains as staple food the subsidy will have a substitution effect and the households will face the subsidized price as the marginal price and this will result in consumption towards more expensive source of calories. But this gives little insights into the impact of TPDS on nutritional status. The result derived from this study is that the food price subsidy program not only fails to improve nutrition(jensen, april 2008) but also changes the consumption patterns among the households which is an unintended and undesirable effect of the policy through its impact on agricultural market. Households are consciously willing to trade large amount of calories for other food characteristics and non-food. The findings from this study also imply that the massive allocation of resources planned under the Right to Food Program in India is not likely to reduce undernourishment. The subsidy also has a positive effect on the consumption of other different food groups even if the subsidy is provided on cereals only. A household's improvement in dietary nutrient intake from such program finally depends on intra family distribution. For example, according to Kennedy (1983), in Mexico where subsidy in milk was provided only to the children, the program resulted in increment of calories intake for the children coming from milk, but total calorie consumption by the children increased less than household consumption.

(Ravallion, 1990)showed that the calorie response to income is higher for the lowest income households than for the household with average income level. (Anand \& Ravallion, 1993)demonstrate that the real income growth from subsidy program facilitates access to health and education services which may contribute in reducing secondary malnutrition.

Effect of subsidy on nutrition depends on the different stages of development of the recipient household, for instance, poor households in Chattisgarh responded to a food grains subsidy by substituting towards pulses which is a cheaper source of nutrition than meat. However if households were richer and pulses constituted a large portion of their diet then their consumption pattern will be different. Their consumption would shift towards meat and nonfood goods decreasing their calorie intake reducing the overall nutritional status (Krishnamurthy, Pathania, \& Tandon, 2014).

Therefore according to Miller and Kaushal; giving subsidy will not only decrease calorie intake due to income effect but will also change the consumption pattern towards more expensive source of calories which can be a potential reason for the failure of the food subsidy program in India.

Henceforth this paper will try to observe experiences from other countries to see if there is any scope of improvement in the food subsidy programs in India.

\section{EMPIRICAL EVIDENCE FROM OTHER COUNTRIES}

Despite the results of theoretical models and bad performance of PDS program in India empirically it has been seen that price subsidy program can be successful in improving the nutritional status of the households if appropriate conditions are met. 
International Journal of Trend in Scientific Research and Development (IJTSRD) ISSN: 2456-6470

Philippines faced a widespread problem of malnutrition in the country,(Marito Garcia, August 1987) Pilot subsidy scheme was introduced in three provinces for a period of 12 months in the country in 1983, price of two calorie rich foods, rice and edible oil were subsidised. Another important component of the scheme is nutrition education which was targeted to change the behaviour of beneficiaries related to food consumption, firstly, to encourage optimal use, to ensure that food consumption and make people aware of the nutritional benefits realized from the rice and cooking oil subsidy; and secondly to help in improving child feeding practices simultaneously. Outreach was high, mothers, being the primary recipients of the nutrition education scheme, regularly attended classes. Participation rate was as high as $90 \%$. A randomized control trial was done in which the scheme was made available to half of 14 villages selected where the incidences of malnutrition and poverty was very high and other half acted as a control population. The sample which was chosen for giving subsidy, a coded, non-transferable card, and ration card was issued to each household which showed the monthly quota based on the household size. The retail distribution outlets chosen to supply the subsidised food items were the neighbourhood variety stores (called sari-sari stores) usually located within each village. It is cost effective in a way that no separate shops need to be constructed for distribution. To evaluate the effectiveness of the scheme, a comparative as well as multivariate analysis was done which showed that the impact of this pilot price subsidy scheme on household food expenditures and nutrition intake was highly significant.

Scheme was successful, leading to increment of food consumption among participating households. Although the additional food items were asymmetrically distributed between adults and preschool children within the households, favouring preschoolers as they consumed more calories and showed improvement in their nutritional status. It led to a net increase in calories acquired by the sample households by 136- 138 calories per day, which is roughly seven percent of current calorie consumption, calorie consumed by pre-schoolers also increased by 31 - 55 calories per child per day(Marito Garcia, August 1987). The effects of educating the households about nutrition were positive and significant for children but overall the impact at household level was weak. Major advantage of this subsidy scheme, it was cost effective as geographical targeting was done which uses the existing private sector retail outlets for the distribution of subsidized foods. Advantage of nutrition education is that it ensures that the households spend a major share of their additional income on food for the nutritiondeficient household members. Interaction effect of the nutrition education with food subsidies showed that information about nutrition is very much valuable in conjunction with increased food consumption. This information is useful in a developmental as well as in distributional context.

Food subsidy program of Egypt is one of the most crucial examples which improved nutritional status. According to (Richard H. Adams, 2000) it is possible to shield the household from malnutrition by providing subsidy to cheap and calorie-dense foods like coarse bread and coarse wheat flour. To tackle the problem of error of inclusion of non-needy people in subsidy program, Egypt followed self-targeting. Program was designed to benefit the intended beneficiaries; subsidy was given on inferior food items which were consumed mostly by poor people who are needy one. This finding was consistent for the case of subsidy in Egypt as coarse baladi bread was a dominant component of food subsidy which was consumed majorly by poorest people both in absolute and relative manner which signifies the property of inferior good. Thus, giving subsidy to these inferior goods resulted in self-selection thus increasing the intended benefits of the scheme. Therefore looking at the international experience, revamp of distribution system in India can be done to improve the nutritional status of intended beneficiaries.

Another potential approach towards increasing the calorie intake can be seen from the models of Kochar and Miller, if the substitution effect explained as high participation rate in the PDS program is greater than the income effects which lead to decrease in calorie intake as Miller argued then calorie intake will improve. Implicitly Kochar arguments are based on the take up rates which elucidates that high take up rates can result in improvement in nutritional status. A program can be designed so that subsidy is given in calorie rich staple food, so that the effect of high participation rate overcomes the negative impact of income effect explained by Miller. 
International Journal of Trend in Scientific Research and Development (IJTSRD) ISSN: 2456-6470

\section{CONCLUSION}

In most of the studies discussed above there is a similar trend observed that the subsidy program has a negligible impact on improving the nutritional status. It is imperative that government design a price subsidy program in such a way that the subsidy amount is not very small as it would lead to low take up rates or participation by the households (Kochar, 2005), at the same time the subsidy is not very large as it can create a large wealth effect and thus there will be substitution towards non nutritional items leading to reduced calorie intake(jensen, april 2008). The above results can be interpreted in terms of the recipient household behaviour who prefers short term utility gains by consuming goods on the basis of taste and preference, even if they are losing on the calorie intake. This shows that households are utility maximizer but they are heavily discounting their future by postponing their calorie need which results in lower nutritional status ultimately affecting the labour productivity. Justification for providing subsidies is that it insures the marginalised households from the frequent fluctuation in prices and it is also easy to administer and have high political support. However they are inflicted by poor targeting excluding the desired intended beneficiaries and including ineligible households.

\section{Bibliography}

1) Anand, S., \& Ravallion, M. (1993). Human development in poor countries:on the role of private incomes and public services. American Economic Association, 133-150.

2) Aziz, F. (August 1995). NUTRITION, HEALTH AND LABOR PRODUCTIVITY.

3) Bunsha, D. (2002, january). The Human Face of Adjustment. Frontline, pp. 5-18.

4) h, 1. (1957). Economic Backwardness and Economic Growth.

5) jensen, m. (april 2008). Do Consumer Price Subsidies Really Improve Nutrition?

6) kaushal, N., \& Muchomba, F. (2013, september). How consumer price subsidies affect nutrition. NBER Working paper series, 1-39.
7) Kochar, A. (2005, october). Can targeted Food Programs Improve Nutrition? An Empirical Analysis of India's Public Distribution System. Chicago Journals, 54(1), 203-235.

8) Krishnamurthy, P., Pathania, V., \& Tandon, S. (2014). Food price subsidies and nutrition:Evidence from state reforms to India's Public Distribution System. Agricultural and Applied Economics Association . Minneapolis.

9) Leibenstien, H. (1957). Economic Backwardness and Economic Growth. John Wiley and sons.

10) Marito Garcia, P. P.-A. (August 1987). THE PILOT FOOD PRICE SUBSIDY. International Food Policy Research Institute.

11) Ministry of Consumer Affairs, F. a. (2002). Food and Public distribution. delhi: Controller of publications, Government of India.

12) Radhakrishna, R. (1991). Food and Nutrition challenges for Policy . Journal of Indian society of Agricultural Statistics, 211-228.

13) Ravallion, M. (1990, April). Income effects on undernutrition. chicago journals, 489-515.

14) Richard H. Adams, J. (2000, october). Selftargeted subsidies: The political and Distributional Impact of the Egyptian Food Subsidy System. chicago journals, 49(1), 115-136.

15) Strauss, J. (1986). Does Better Nutrition Raise Farm Productivity? Journal of Political Economy.

16) Valero, J., \& Valero, M. (2014, september). Nutrition and poverty during a prolonged crisis.

17) Viteri, F. E. (1971). Considerations on the Effect of Nutrition on the Body. MIT Press.

18) Weinberger, K. (n.d.). Micronutrient intake and labour productivity. 